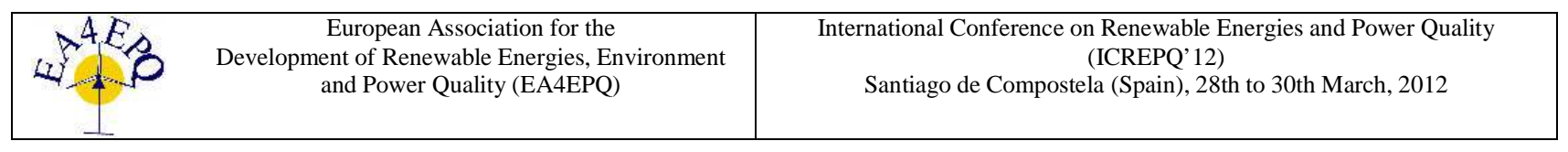

\title{
Investigating University Personnel Computers (PC) Produced Harmonics Effect on line Currents
}

\author{
M. H. Shwehdi ${ }^{1}$, F. S. AL-Ismail ${ }^{2}$ \\ ${ }^{1}$ Electrical Engineering Department, King Faisal University \\ ${ }^{2}$ Electrical Engineering Department, King Fahd University of Petroleum \&Minerals \\ mshwehdi@kfu.edu.sa
}

\begin{abstract}
Nonlinear loads connected to a sinusoidal source inject harmonic currents into the source. Nonlinear load is a load that draws none sinusoidal current wave when supplied by a sinusoidal voltage source. Much attention has been focused on large power converters as sources of harmonics due to the high magnitude of the currents evolved. Nevertheless, harmonics generated by low power converters become significant when large numbers of converters are used simultaneously. In this paper the influence of the personal computers in the line current harmonics in some buildings at King Fahd University of Petroleum and Minerals (KFUPM) have been investigated. The harmonics were monitored from the main switched boards of each building that has the highest number of PC's and from the switch boards of each computer labs in these buildings. This investigation may help in pinpointing the harmonic generating sources, effects, and how to mitigate, also to obtain the actual PC operation of the university and its harmonic contribution. Measurements indicate that two buildings of the highest PC's numbers do have harmonics but one building harmonics is higher than that allowed by IEEE-519 standards [1] limits and the other does not influence phase current and it is within allowable limits.
\end{abstract}

\section{Key Words}

Nonlinear Loads, Total Harmonic Distortion, Harmonics, Line Currents, Personal Computers University, Saudi Arabia

\section{Introduction}

KFUPM is utilizing all modern technology tools to make it available to faculty and students as well as making most of its services to be handled electronically. Smart card mode has been used in most of the buildings and parking lots, upgrades of most laboratories on digital operations, such new automation and facilities are nonlinear producing elements and contribute current harmonics to the interconnected university system.

This concern remains of topical importance since large concentrations of PC's, and laser printers which are microprocessor-based controls and other power electronics devices and are sensitive to Power Quality (PQ) disturbances, are increasingly found in offices, student's laboratories, classrooms, high density residential areas, markets, restaurants, etc... inside the campus. PQ problems are increasing with the proliferation of nonlinear devices, which draw none sinusoidal current waveforms when supplied by a sinusoidal voltage source. When these devices are present in an electric power system, they cause harmonic distortion of voltages and currents. Individually, single phase nonlinear load may not pose many serious harmonic problem, but large concentrations of these loads have the potential to raise harmonic voltages and currents to unacceptable high levels which results in increased neutral currents in four wire system, over heating of distribution system components and may cause mechanical oscillations in generators and motors. Other unwanted effects are capacitor and insulation failure due to harmonic resonance, malfunction of installed protection systems, transient voltage fluctuations, over heating of system transformer and cables, error of power electronic equipments operations and telephone interference. Studies on the monitoring of PQ at computer sites have been conducted as early as 1969, [2, 3], and continuing interest in this area has maintained regular publications thereafter [4, 5, and 6]. Most early studies were concerned with the effects of power disturbances on the correct operation of the computer facility. However, with the advent of relatively inexpensive personal computers (PC), the emphasis of computer power quality monitoring has also moved towards investigating the effects that large concentrations of PCs can have on other utility customers. Personal computing impacts on $\mathrm{PQ}$ are increasing due to the common place usage of switched mode power supplies (SMPS) for converting single phase AC into low voltage DC for supplying processing electronics. Such power supplies, which are responsible for the generation of odd line current harmonics, are the main concern of this paper. However, in turn harmonically polluted line currents can distort supply voltages causing power quality problems for other consumers connected at a point of common coupling [7]. Additionally, and somewhat ironically, the switched mode power supply itself can be affected by nonsinusoidal supply voltages [8], which can increase or decrease current harmonics depending on the nature of the voltage distortion. A recent study [9] has shown that the line current harmonics from a single PC differed considerably to the harmonics generated collectively by several PCs of the same type. One widely held theory [10] regarding this effect introduces the concepts of attenuation and diversity. Attenuation describes the reduction in harmonic magnitude, and change in phase angle, as a load connected to a SMPS 
increases, and attributes this effect to the change in the spectrum of the line current pulse which widens to allow more power flow through the SMPS [11-12]. In view of the concerns regarding cumulative effects of large collections of PCs, this study was conducted within a University library building containing over 370 PCs. Furthermore, the study was intended to investigate the primary effect on line current harmonics caused by mode of operation, in isolation from additional secondary effects caused by distorted supply voltages. Investigation of this primary effect was achieved by monitoring during periods when the PCs represented the only load on the transformer supplying the library building and consequently the supply voltage waveforms were relatively undistorted. Most of these disturbances originate right within the building. Personal computers, laser printers and other switched-mode power supply equipment within your building are usually the culprits for most of the power supply irregularities affecting other computers. It's a problem that has only recently begun to be recognized in the building industry, as more and more computers and similar equipment are installed, turning the modern office or factory into a high-tech computer environment [13]. The objective of this paper is to investigate the effect of the KFUPM-PC and other harmonic contributing sources on the line currents that may have influence on processing modes and to measure the actual Total Harmonic Distortion during such modes.

The phase current is given by:

$$
I p=\sqrt{\left(I 1^{2}+I 3^{2}+I 5^{2}+I 7^{2}+I 9^{2}+I 11^{2}+I 13^{2}+I 15^{2}\right)}
$$

The IBM XT ${ }^{\mathrm{TM}}$ has the lowest percent third harmonic current (74\%). Since the computer is connected line-to-neutral in a 3phase system, the neutral current is approximately equal to three times the vector sum of the third and ninth harmonic currents flowing in each phase.

$$
\begin{aligned}
& \text { In }=3 \sqrt{13^{2}+19^{2}}=367.764 m A \\
& I p=219.226 m A \\
& \frac{I n}{I p}=1.677
\end{aligned}
$$

The Mac Plus TM offers the worst case third harmonic current (87\%). In a similar manner In \& Ip are obtained.

$$
\begin{aligned}
& \text { In }=223.377 m A \\
& \text { Ip }=130.507 m A \\
& \frac{\text { In }}{\text { Ip }}=1.712
\end{aligned}
$$

With a large number of personal computer loads, the neutral current is expected to be 1.7 times the phase current. It will certainly overload the neutral conductor that is designed to handle lower currents than the phase currents $[1,14]$.

\section{A. BACKGROUND}

The campus of King Fahd University of Petroleum and minerals consists of 60 buildings including students housing. KFUPM is considered as one of the best Universities in the Middle East since its staff uses the most modern technologies in teaching, research, facilities and the interaction between the students. Almost each student at KFUPM has a laptop regardless of the number of $\mathrm{PCs}$ in each, laboratories, or room at KFUPM. According to the most recent statistics provided from information technology center (ITC) at KFUPM shows that there are around 6000 PCs distributed unequally in the Mostly the personal computers in KFUPM are of model HP, DELL, Compaq dc 7800P; they use Intel core 2 Dual processors.

\section{B. Standards and Limits}

International Standards have set some limits to the most equipment on the permissible harmonic content in the electrical system during operation. The following are general limits for various electrical equipments:

a. Synchronous machine: permissible stator current distortion $<1.4 \%$

b. Asynchronous machines: permissible stator current distortion; $1.5 \%$ to $3.5 \%$

c. Cable: permissible core-shielding voltage distortion < $10 \%$

d. Electronic equipment: 5\% voltage distortion with a maximum individual percentage of $3 \%$ depending on the equipment

e. Transformer: permissible current distortion $<5 \%$ at full load [ IEEE-519]

Most utilities have adopted standards to limit the harmonic content at the point of common coupling (PCC). Some of the Standards adapted around the world include:

- US/Canada IEEE 519

- $\quad$ Europe IEC61000 3-2, 3-4

- United Kingdom G5/4 -1

- China GB/T 14549

\section{Measurement plan}

This investigation adapted the following steps which include:

- Obtaining all line diagrams of the area of investigation.

- Securing the total number of KFUPM PC's and most PC's concentration area.

- Circulate Questionnaire to major PC users such as ITC to develop a sense where are the major area that may have harmonics as to affect ITC line currents and servers etc...

- $\quad$ Locate and prepare the building (14, consist of 263 PC's and 58 consist of 280 PC's) switchboard to be able to conduct different measurements being the highest building containing PC's.

- Conduct Harmonic measurements at these buildings and monitor and check harmonics at different loading processing modes and times.

- Recommendation and findings are to be clearly drawn out of results and stressing the mode of operations and size of PC lab. 
- Identify the sources and causes of harmonics at such selected locations: use such data in the process of making the appropriate mitigating actions.

Due to the size of KFUPM and the time limit to conduct this investigation, it was decided to select the highest PC number two buildings mentioned.

\section{Measurement Procedure}

To conduct harmonic measurement the team members attended intensive lectures and training on Power Quality and measurements. Training focused on how to use the power quality analyzer (PQA) made by Fluke model 43 B. Single line diagrams for each of the building under investigate were obtained as shown in Figure 1. Permissions to conduct measurement and open switch boards of the different feeders were also obtained through the KFUPM Electrical Maintenance department.

The whole Excl file containing total PC's provided by from ITC indicating all KFUPM PC's record and their distributions at the different building and labs.

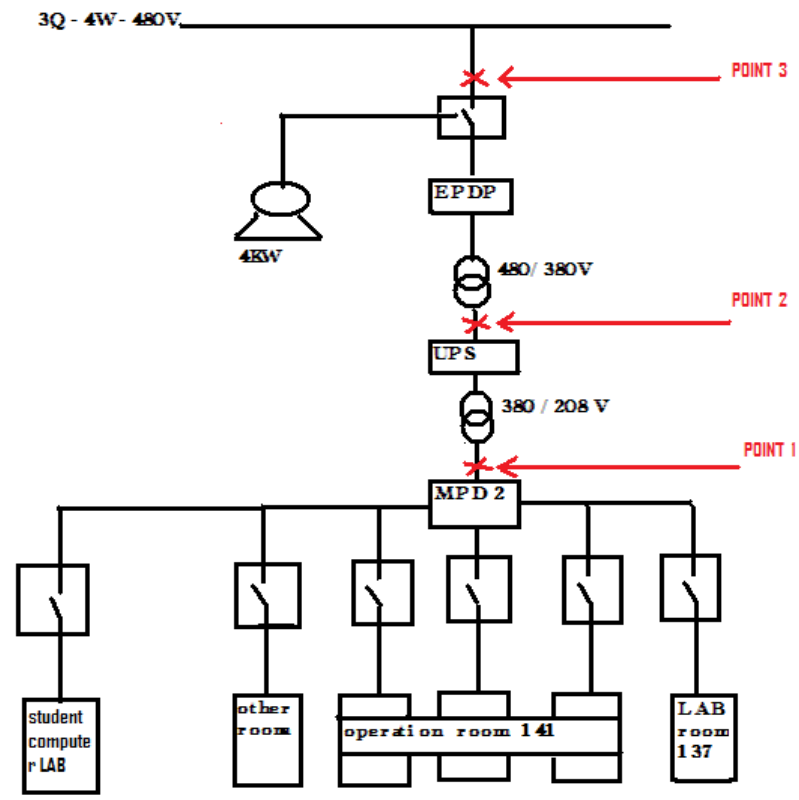

Fig.1. Building 14 Single Line Diagram and Points of measurements and switch boards

\section{Measurements and Results}

The measurement of the harmonics caused by PC's and any other nonlinear elements were conducted at each bus (points 1, 2 , and 3 ) as indicated in the single line diagram. At the first point shown in the single line diagram Figure 1, three measurements have been conducted over three periods. The THD during the first period at point one was measured and the maximum total harmonic distortion (THD) was $10.6 \%$. The THD during the second period at point one and the maximum total harmonic distortion (THD) was $10.7 \%$. The THD during the third period at point one and the maximum total harmonic distortion (THD) is $10.8 \%$ From the previous three readings it is clear that at normal load at point one the maximum total harmonic distortion of the three readings is $10.8 \%$. Moreover, the harmonics effect appears in the current waveform as in Figure 2 .
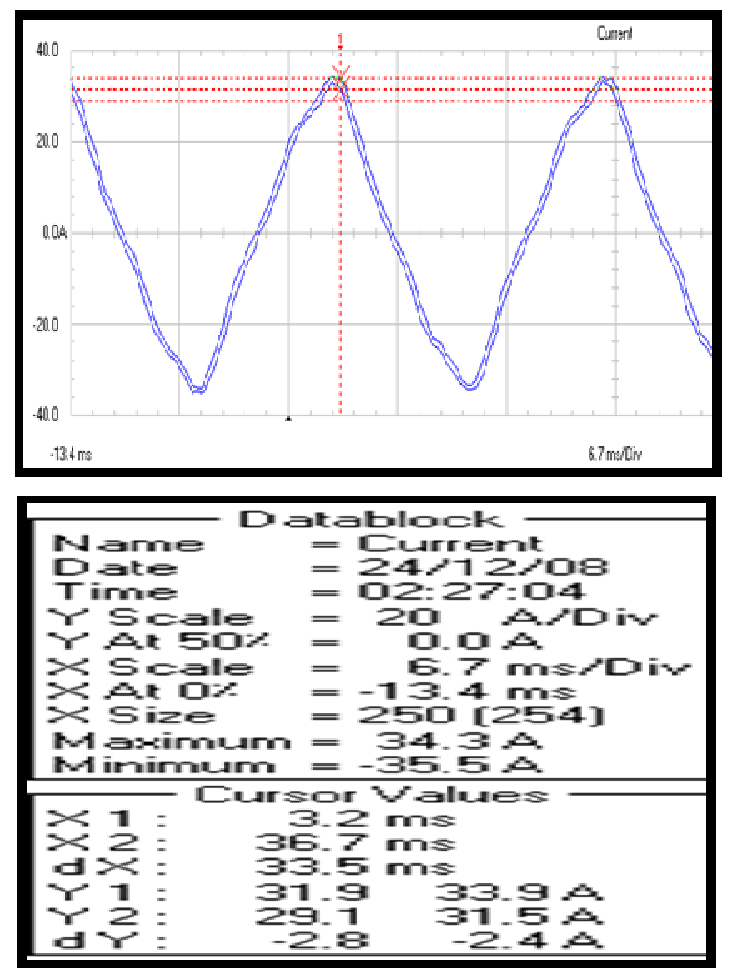

Fig.2. Current wave forms at point one

For the second point the THD during the first period indicated a maximum total harmonic distortion (THD) was $29 \%$. On the second measuring period the THD during the second period at point one and the maximum total harmonic distortion (THD) was $28.4 \%$. Exact capture shown in Figure 3 shows the curve of the THD during the third period at point two and the maximum total harmonic distortion (THD) was $28.9 \%$.

From the previous three readings it is clear that at normal load at point two increases the harmonic flow, the maximum total harmonic distortion of the three readings is $28.9 \%$. Moreover, the harmonics appears to distort the phase current waveform as in Figure 4.

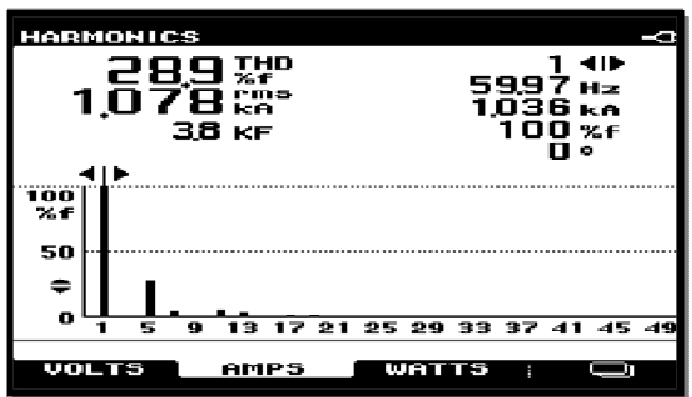

Fig.3. Exact capture 

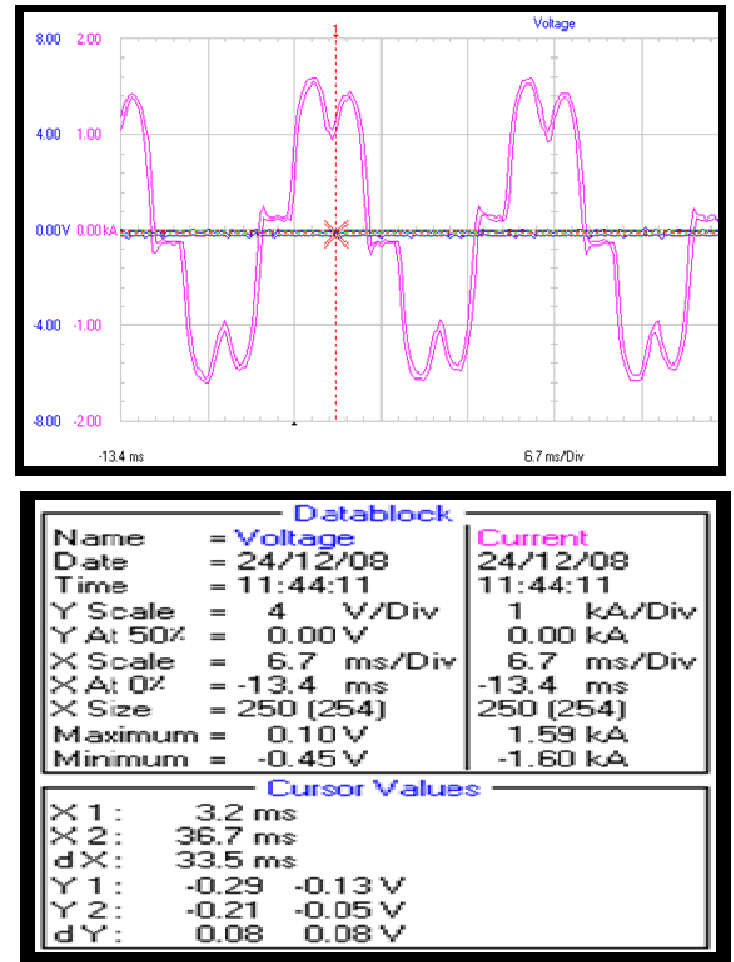

Fig.4. Current wave forms at point two

The sum of all these THD's $=83.8 \%$ is not equal the THD at point one which is $10.8 \%$. The difference between these two values explains which is called harmonic cancellations. The phase angles of the magnetization current harmonics oppose the phase angles of the load current harmonics and such lead to harmonic cancellations. The maximum total harmonic distortion at point three is $20.6 \%$ which is less than that at point two (29\%).The difference between the two values is caused also by harmonics cancellation. According to the instructions provided with the power quality analyzer Fluke 43 B manual and other standards which state that if the current THD is less than $20 \%$ the harmonic distortion is probably acceptable.

\section{VERIFICATION CALACULATIONS}

The percentage of Total Harmonic Distortion (\% THD) can be defined in two different ways, as a percentage of the fundamental component (the IEEE definition of THD) or as a percentage of the RMS (used by the Canadian Standards Association and the IEC).

$\mathrm{THD}=\frac{\sqrt{\sum_{n=2}^{\infty}{ }^{2}}}{I_{1}}$

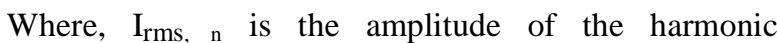
component of order $n$ (i.e., the nth harmonic). The numerator gives the RMS current due to all harmonics and $I_{1}$ is the RMS value of fundamental component of current only. Given above is the mathematical form of the IEEE. According to IEC standards, the mathematical form of THD is given below:

$\mathrm{THD}=\frac{\sqrt{\sum_{n=2}^{\infty}{ }^{2}}}{I_{1}}$

Where

$\mathrm{I}_{\mathrm{rms}}=\sqrt{\sum_{n=1}^{\infty}{ }^{2} \text { Irms }}$

Where $I_{r m s, ~}$ is the amplitude of the harmonic component of order $n$ (i.e., the nth harmonic) and $\mathrm{I}_{\mathrm{rms}}$ is the rms value of all the harmonics plus the fundamental component of the current. The later standard is referred in this study, because the apparatus used for analysis was based on IEC Standards.

The 3rd, 5th, 7th and 9th harmonics being the most significant, the definition of THD may be modified

Table 5 Harmonic magnitudes for different No. of PC's at point 1

\begin{tabular}{|c|c|c|c|c|c|c|c|c|c|}
\hline $\begin{array}{l}\text { No. } \\
\text { of } \\
\text { PC's }\end{array}$ & $\begin{array}{l}\% \text { age } \\
\text { Mag. } \\
\text { of } 3^{\text {rd }} \\
\text { Harmonic }\end{array}$ & $\begin{array}{l}\% \text { Mage } \\
\text { of } 5^{\text {th }} \\
\text { Harmonic }\end{array}$ & $\begin{array}{l}\% \text { age } \\
\text { Mag. } \\
\text { of } 7^{\text {th }} \\
\text { Harmonic }\end{array}$ & $\begin{array}{l}\text { \%age } \\
\text { Mag. } \\
\text { of } 9^{\text {th }} \\
\text { Harmonic }\end{array}$ & $\begin{array}{l}\text { \%age } \\
\text { Mag. } \\
\text { of } \\
11^{\text {th }} \\
\text { Harmonic }\end{array}$ & $\begin{array}{l}\% \text { age } \\
\text { Mag. } \\
\text { of } \\
13^{\text {th }} \\
\text { Harmonic }\end{array}$ & $\begin{array}{l}\text { \%age } \\
\text { Mag. } \\
\text { of } \\
15^{\text {th }} \\
\text { Harmonic }\end{array}$ & $\begin{array}{l}\text { \%age } \\
\text { Mag. } \\
\text { of } \\
17^{\text {th }} \\
\text { Harmonic }\end{array}$ & $\begin{array}{l}\text { THD } \\
\%\end{array}$ \\
\hline 263 & $28.3 \mathrm{~A}$ & $14.8 \mathrm{~A}$ & $5.2 \mathrm{~A}$ & $0.4 \mathrm{~A}$ & $0.7 \mathrm{~A}$ & $0.1 \mathrm{~A}$ & $0.4 \mathrm{~A}$ & $0.1 \mathrm{~A}$ & 10.4 \\
\hline 170 & $27.1 \mathrm{~A}$ & $13.1 \mathrm{~A}$ & $4.6 \mathrm{~A}$ & $1.4 \mathrm{~A}$ & $0.7 \mathrm{~A}$ & $0.4 \mathrm{~A}$ & $0.7 \mathrm{~A}$ & $0.1 \mathrm{~A}$ & 9.9 \\
\hline
\end{tabular}


and written as in 3.4

$\mathrm{THD}=\frac{\sqrt{I_{r m s, 3}^{2}+I_{r m s, 5}^{2}+I_{r m s, 7}^{2}+I_{r m s, 9}^{2}}}{I_{r m s}}$

The value of THD may be calculated for any number of computers using formula (3.3).

$\mathrm{I}_{\mathrm{rms}}=308.4 \mathrm{~A}$

RMS magnitude of 3rd Harmonic $=25.6 \mathrm{~A}$

RMS magnitude of 5th Harmonic $=12.5 \mathrm{~A}$

RMS magnitude of 7th Harmonic $=4.2 \mathrm{~A}$

RMS magnitude of 9th Harmonic $=1.8 \mathrm{~A}$

$$
T H D=\frac{\sqrt{\left(25^{*} 6^{2}+12 * 5^{2}+4 * 2^{2}+1 * 8^{2}\right)}}{308 * 4}=9.36 \%
$$

Figure 5 is showing the magnitude of individual harmonics, when $263 \mathrm{PCs}$ in building 14 were connected to the supply mains.

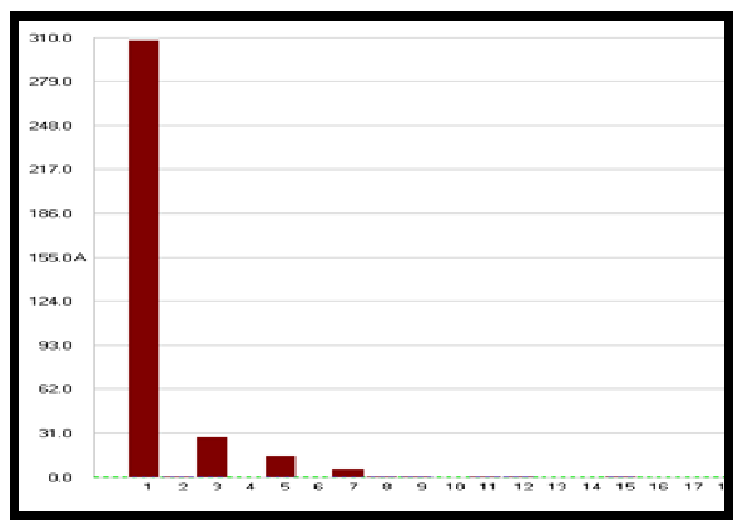

Fig. 5. Harmonic spectrums at point one when 263 PC's operating

The online value of THD was $9.6 \%$. The percentage difference (Error) of the calculated and experimental value is $0.24 \%$. This difference caused by neglecting other odd harmonics such small error proves the validity of measurement using this PQA and it consequently plays a pivotal role for the accurate analysis of the odd harmonics.

The value of THD may be calculated for any number of computers with formula (3.4).

By using linear interpolation, fig 6 the relation between THD and current and the number of PC's $(\mathrm{N})$ is given by the following equation:

It $=31.91-0.019 \times \mathrm{N}$

Where 9.6 is the online THD value. Such equation is derived as regression and it can be applied.

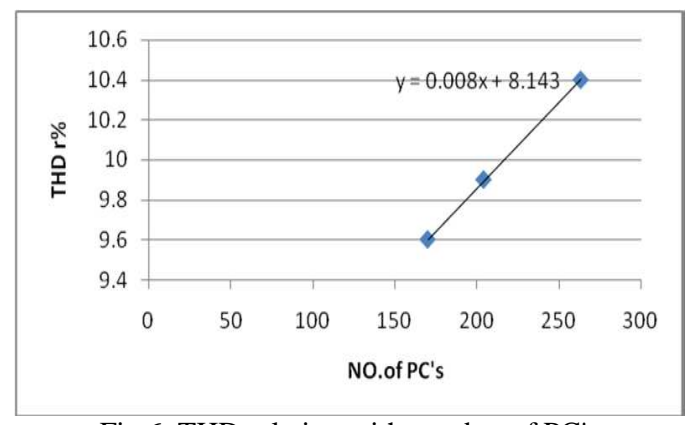

Fig.6. THD relation with number of PC's

\section{Real THD Measurements Discussion}

According to the previous measurements it has been observed that the total harmonic distortion at point two $(29 \%)$ is much greater than that at point one $(10.8 \%)$. Since there is no load connected between these two points except the Uninterruptible power supply (UPS), it is considered that UPS is the main reason for this difference. The UPS can be considered to fit 'in-line' between the loads and the mains power supply. In addition to providing power protection to the loads, it should also protect the main power supply itself from getting any harmonics generated by the loads themselves. Care has to be taken when comparing different THD values as these can differ when contrasting the two different types of on-line UPS (transformer-based and transformer less) and also with regard to the percentage of load applied for each measurement. For transformer-based UPS, rectifiers are typically six or twelve-pulse, dependent upon the thyristor number and configuration. A six-pulse rectifier at full load will typically generate a THD of around $29 \%$ and a 12-pulse around $8 \%$. To reduce these values further a passive harmonic filter can be installed alongside the UPS. The obvious disadvantages of this approach being increased capital cost, wiring, installation, loss of efficiency and increased footprint. Harmonic filters can be added post-installation but further installation costs and downtime need to be planned for. The maximum total harmonic distortion at point three is $20.6 \%$ which is less than that at point two (29\%).The difference between the two values is caused also by harmonics cancellation.

\section{CONCLUSIONS}

The following conclusions can be drawn from the results of this study. The switch mode power supply (SMPS) used in personal computers draws a non linear current that is rush in harmonics currents. A high density of (SMPS) loads results in over loading of the neutral 
conductor and the overheating of the distribution transformers.

The assessment of odd harmonics in current significant in magnitudes are represented by mathematical modeling a proved theoretically the decrease in THD in current at some points when increasing the number of PC's connected to these points. On the other hand, THD increased with increase the number of PC's on the other points of these buildings. According to this study the maximum THD found was $29 \%$ in the main student lab in building 14 and it was unstable and the minimum THD was found $1.1 \%$ in building 58 which is the second high in PC's number.

As many standards indicate and provide and state that if the current THD is less than $20 \%$ the harmonic distortion is probably acceptable, the total harmonic distortion at point three of building $14(29 \%)$ is greater than $20 \%$ is not acceptable and makes affect on the neutral line cable. To avoid the injection of harmonics into the system, a harmonic filter must be installed depending on how high are the harmonics level. In this case we can do by connecting larger side cables.

Due to the highly non sinusoidal nature of the input current waveform of personal computer, the high amplitude of harmonics currents are generated. These harmonics currents are of odd order because of half wave symmetry of the input current waveform. The magnitudes of the harmonics currents up to the seventh harmonics are significant due to the six-pulse bridge of the UPS.

A six-pulse rectifier at full load will typically generate a THD of around $29 \%$ and a 12-pulse around $8 \%$. That is also why it shown that $3^{\text {rd }}$ harmonics are smaller than e.g. $5^{\text {th }}$ harmonics as shown in fig 5 . According to the above results obtained from this study, THD at point 2 is (29\%) of building 14 does not guarantee with IEEE 519 standards $(<20 \%)$ this well cause to reduce the life time of the transformers wiring, and cables in building 14 .

\section{Acknowledgement}

The authors appreciate the publication support of the College of Engineering at KFU-AL-Ahsa and KFUPM in Dhahran.

\section{References}

[1] IEEE recommended practices and requirements for harmonic control of electrical power systems, IEEE Std. 519-1992, 1993

[2] G. W. Allen, "Design of power-line monitoring equipment,” IEEE Trans. Power App. Syst., vol. PAS90, no. 6, Nov./Dec. 1971.
[3] T. S. Key, "Diagnosing power quality-related computer problems", IEEE Trans. On Industry Applications, vol IA-15, no.4, July-August 1979, pp381-393.

[4] M. Goldstein and P. D. Speranza, "The quality of U.S. commercial ac power," in Proc. INTELEC Conf., 1982.

[5] R. Odenberg and B. Braskich, "Measurements of voltage and current surges on the ac power line in computer and industrial environments," IEEE Trans. Power App. Syst., vol. PAS-104, no. 10, Oct 1985, pp 2681- 2688.

[6] L. I. Eguiluz, M. Mañana and J. C. Lavandero, "Voltage distortion influence on current signatures in non-linear loads", Proc of IEEE PES Winter Meeting 2000, CDROM 0-7803-6423-6.

[7] D. O. Koval, C. Carter, "Power quality characteristics of computer loads", IEEE Trans. Industry Applications, vol. 33, issue 3, May-June 1997, pp. 613-621.

[8] A. Mansoor, W. M. Grady, A. H. Chowdury and M. J. Samotyj, "An investigation of harmonics attenuation and diversity among distributed single-phase power electronic loads", IEEE Trans. Power Delivery, vol. 10, no. 1, January 1995 , pp. 467-473.

[9] A. Mansoor, W. M. Grady, P. T. Staats, R. S. Thallam, M. T. Doyle and M. J. Samotyj, "Predicting the net harmonic currents produced by large numbers of distributed single-phase computer loads," IEEE Trans. Power Delivery, vol. 10, no. 4, Oct 1995, pp. 2001-2006.

[10] Capasso, R. Lamedica, A. Prudenzi, "Experimental characterization of personal computers harmonic impact on power quality," Computer Standards \& Interfaces 21 (1999), pp. 321-333.

[11] P. J. Moore and I. E. Portugues, "The Influence of Personal Computer Processing Modes on Line Current Harmonics", IEEE Transactions on Power Delivery, Volume: 18, Issue: 4, pp: 1363- 1368, Oct. 2003.

[12] H. O. Aintablian, H. W. Hill, Jr "Harmonic Currents Generated by Personal Computers and their Effects on the Distribution System Neutral Current", IEEE Industry Applications Society Annual Meeting, 1993, Canada, Volume: 2, pp: 1483-1489, 2-8 Oct 1993.

[13] Rana Abdul Jabbar Khan and Muhammad Akmal, "Mathematical Modeling of Current Harmonics Caused by Personal Computers", International Journal of Electrical and Electronics Engineering, pp: 103-107, 3:2, 2008. 